University of Nebraska - Lincoln

DigitalCommons@University of Nebraska - Lincoln

2010

Development and evaluation of a cloud-gap-filled MODIS daily snow-cover product

\author{
Dorothy K. Hall \\ NASA Goddard Space Flight Center \\ George A. Riggs \\ NASA Goddard Space Flight Center \\ James L. Foster \\ NASA Goddard Space Flight Center \\ Sujay V. Kumar \\ NASA Goddard Space Flight Center
}

Follow this and additional works at: https://digitalcommons.unl.edu/nasapub

Part of the Physical Sciences and Mathematics Commons

Hall, Dorothy K.; Riggs, George A.; Foster, James L.; and Kumar, Sujay V., "Development and evaluation of a cloud-gap-filled MODIS daily snow-cover product" (2010). NASA Publications. 59.

https://digitalcommons.unl.edu/nasapub/59

This Article is brought to you for free and open access by the National Aeronautics and Space Administration at DigitalCommons@University of Nebraska - Lincoln. It has been accepted for inclusion in NASA Publications by an authorized administrator of DigitalCommons@University of Nebraska - Lincoln. 


\title{
Development and evaluation of a cloud-gap-filled MODIS daily snow-cover product
}

\author{
Dorothy K. Hall ${ }^{\text {a,* }}$, George A. Riggs ${ }^{b}$, James L. Foster ${ }^{c}$, Sujay V. Kumar ${ }^{\text {d }}$ \\ a Cryospheric Sciences Branch, NASA Goddard Space Flight Center, Greenbelt, MD, 20771, United States \\ b Science Systems \& Applications Inc., and Cryospheric Sciences Branch, NASA Goddard Space Flight Center, Greenbelt, MD, 20771, United States \\ ${ }^{c}$ Hydrological Sciences Branch, NASA Goddard Space Flight Center, Greenbelt, MD, 20771, United States \\ d Science Applications International Corporation, and Hydrological Sciences Branch, NASA Goddard Space Flight Center, Greenbelt, MD, 20771, United States
}

\section{A R T I C L E I N F O}

\section{Article history:}

Received 9 July 2009

Received in revised form 28 September 2009 Accepted 2 October 2009

\section{Keywords:}

MODIS

Snow cover

SWE

Data assimilation

LIS

\begin{abstract}
A B S T R A C T
The utility of the Moderate Resolution Imaging Spectroradiometer (MODIS) snow-cover products is limited by cloud cover which causes gaps in the daily snow-cover map products. We describe a cloud-gap-filled (CGF) daily snow-cover map using a simple algorithm to track cloud persistence, to account for the uncertainty created by the age of the snow observation. Developed from the $0.05^{\circ}$ resolution climate-modeling grid daily snow-cover product, MOD10C1, each grid cell of the CGF map provides a cloud-persistence count (CPC) that tells whether the current or a prior day was used to make the snow decision. Percentage of grid cells "observable" is shown to increase dramatically when prior days are considered. The effectiveness of the CGF product is evaluated by conducting a suite of data assimilation experiments using the community Noah land surface model in the NASA Land Information System (LIS) framework. The Noah model forecasts of snow conditions, such as snow-water equivalent (SWE), are updated based on the observations of snow cover which are obtained either from the MOD10C1 standard product or the new CGF product. The assimilation integrations using the CGF maps provide domain-averaged bias improvement of $\sim 11 \%$, whereas such improvement using the standard MOD10C1 maps is $\sim 3 \%$. These improvements suggest that the Noah model underestimates SWE and snow depth fields, and that the assimilation integrations contribute to correcting this systematic error. We conclude that the gap-filling strategy is an effective approach for increasing cloud-free observations of snow cover.
\end{abstract}

(c) 2009 Elsevier Inc. All rights reserved.

\section{Introduction}

Snow-cover map products are important inputs to hydrological and general circulation models (GCMs) and are increasingly being used in data assimilation modeling to improve model forecasts. Snow-cover maps are also used in climatological studies such as for analysis of decade-scale hemispheric snow-cover changes (e.g., Frei \& Robinson, 1999; Brown, 2000; Robinson et al., 2001; Armstrong \& Brodzik, 2001). Data from visible and near-infrared parts of the electromagnetic spectrum are especially useful for snow mapping because of their potentially-high spatial resolution, and the ability to discriminate snow from other features such as clouds. Yet on any given day much of the Earth's surface may be obscured by clouds thus limiting our ability to monitor snow cover using sensors operating in the reflective part of the electromagnetic spectrum.

The Moderate Resolution Imaging Spectroradiometer (MODIS) snow-cover map products (Hall et al., 2002; Hall \& Riggs, 2007) have been used for hydrological, climatological and modeling applications (also see, Rodell \& Houser, 2004; Déry et al., 2005; Tekeli et al., 2005;

\footnotetext{
* Corresponding author.

E-mail addresses: dorothy.k.hall@nasa.gov (D.K. Hall), george.a.riggs@nasa.gov (G.A. Riggs), james.l.foster@nasa.gov (J.L. Foster), sujay.v.kumar@nasa.gov (S.V. Kumar).
}

Wang et al., 2005; Zhou et al., 2005; McGuire et al., 2006; Brown et al., 2008; Bavera \& Michele, 2009). The fully-automated nature of the MODIS snow-cover algorithms also make the products useful for developing and augmenting long-term snow-cover records and climate-data records. To alleviate gaps in coverage caused by clouds, several researchers have developed methods to mitigate the cloud obscuration.

In this paper, we describe a simple technique using a standard MODIS snow-cover product, MOD10C1, to fill in data gaps caused by clouds; this technique is used to produce a cloud-gap-filled (CGF) daily MODIS snow-cover map. MOD10C1 is a $0.05^{\circ}$ resolution daily snowcover map product derived from the Terra MODIS that includes snowcover fraction (SCF) in each grid cell and is presented on a latitude/ longitude grid known as the climate-modeling grid (Riggs et al., 2006). Terra MODIS data are available from February 2000 to the present. The CGF product can provide complete daily snow coverage irrespective of clouds, and the associated viewing confidence is provided on a per-gridcell basis. The age of the observation is included with each cell of the product. We evaluate the effectiveness of the CGF product by conducting a suite of data assimilation experiments using the community Noah land surface model in the NASA Land Information System (LIS) framework (Kumar et al., 2008). The data assimilation experiments are conducted using both the standard MOD10C1 and the MODIS CGF snow-cover maps. 


\section{Background}

\subsection{The MODIS cloud mask}

The MODIS cloud mask uses cloud-detection tests to indicate a level of confidence that the MODIS is observing clear skies. It is produced globally at 1-km resolution (Ackerman et al., 1998; Platnick et al., 2003). The algorithm uses many of the 36 MODIS spectral bands to maximize cloud detection. The MODIS cloud mask is an ancillary input to the MODIS land, ocean and atmosphere science algorithms including the MOD10C1 snow-cover maps.

\subsection{Gap filling for geophysical research products}

Gap filling is a viable technique for filling in missing data due to swath gaps or cloud obscuration and is used in many disciplines. Gapfilling techniques are particularly useful in products that are used to monitor features that change gradually over time such as vegetation and snow cover in northern latitudes in the winter. For rapidlychanging features like some clouds, or at times of year when features are changing rapidly, gap-filling techniques can introduce more error. Aside from snow, gap-filled products from MODIS have been developed and validated for various products [see for example, Gao et al. (2008) and Borak \& Jasinski (2009) who used gap filling with MODIS leaf-area index data].

Cloud obscuration in snow maps severely limits the temporal continuity of the satellite coverage and as a result severely constrains their use in many end-use applications. Data assimilation systems such as LIS typically use the ancillary quality information (for example, estimates of confidence in the observation and percentage of cloud cover) to determine the reliability of a particular observation before its use in the assimilation process. Cloudobscured observations are typically classified as less reliable, and therefore are not used, leading to information gaps in the snowcover observations. The MODIS CGF snow-cover product was developed to address these gaps by providing a snow-cover map based on the most recent cloud-free observations, along with a count of days since the last recorded view to help determine the reliability of the satellite observation.

\subsection{Some available snow products}

Daily snow-cover maps are obtainable from several U.S. federal agencies that generate them from various data sources. Other countries such as Canada, Finland and Norway, also produce daily snow-cover maps. Snow maps of both hemispheres are available from the National Ice Center (NIC) of the National Oceanic and Atmospheric Administration (NOAA); NIC provides daily snow-cover extent maps, without clouds, at a spatial resolution of $4 \mathrm{~km}$ (Ramsay, 1998; Helfrich et al., 2007), known as the Interactive Multispectral Snow and Ice Mapping System (IMS) product [http://www.natice.noaa.gov/ims/]. The IMS algorithm is not fully automated to allow the analysts the flexibility to take advantage of data from weather stations and other sources that provide useful information on an as-needed basis when cloud cover interferes with satellite-based snow mapping. A multitude of data sources may be employed by the analysts who generate the daily IMS maps. Analysis of successive geostationary satellite images can minimize the limitation imposed by cloud cover based on the fact that clouds generally move faster than snow cover can change, with the clouds often changing perceptibly in very short time spans (Romanov \& Gutman, 2000; Wildt et al., 2007). The NIC analyst may use multiple images from polar and geosynchronous satellites as well as other data sources, e.g., synthetic-aperture radar, passivemicrowave and weather-prediction model output, to enhance mapping of snow extent when the surface is obscured by cloud, and to help distinguish clouds and snow. They may also use the previous day or days of snow maps to infer snow extent.

Using the Advanced Very High Resolution Radiometer Polar Pathfinder (APP) dataset, Zhao and Fernandes (2009) developed a snow-cover algorithm at $5-\mathrm{km}$ resolution that was applied to the Northern Hemisphere and found results to agree well with station data in northern Eurasia and Canada. The APP dataset, developed from the NOAA daily snow-cover maps, provides daily snow cover without clouds, from 1982 to 2004.

Other NOAA products, such as from the National Operational Hydrologic and Remote Sensing Center, provide snow cover and snowwater equivalent (SWE) as well as much additional information on snow cover in the United States and parts of southern Canada [http://www. nohrsc.noaa.gov/nsa/] derived from satellites, airborne, and groundbased data sources and modeling.

\subsection{Cloud-mitigation strategies}

In the standard MODIS snow-cover products http://modis-snowice.gsfc.nasa.gov, the limitation caused by cloud cover has been mitigated by various researchers who have developed techniques to reduce the obscuring effects of cloud cover. Riggs and Hall (2003) developed a "liberal" cloud mask from the MODIS cloud-mask threshold tests that was useful in eliminating false clouds in the standard MODIS snow-cover products, but extensive testing concluded that, while it provided excellent results in some areas of the globe, the liberal cloud mask caused problems in other areas. Thus it is not available as part of the MODIS Collection-5 snow-cover product suite because the MODIS snow-cover algorithm must work well globally, not just in a particular region.

Several researchers have developed cloud-mitigation strategies that employ both Terra and Aqua MODIS data (e.g., see for example, Parajka \& Blöschl, 2008; Wang \& Xie, 2009; Wang et al., 2009; Gafurov \& Bárdossy, 2009); and Tekeli \& Tekeli, submitted for publication). Since the Terra and Aqua satellites have local overpass times in the morning and afternoon, respectively, use of both Terra and Aqua snow maps permits more opportunities to view the surface and can be especially useful when sky conditions are changing rapidly.

Parajka and Blöschl (2008) evaluated three approaches to reduce cloud cover in the standard MODIS snow-cover products: 1) combining Terra and Aqua observations; 2) spatial filtering; and 3) temporal filtering (using 1-7 clear days before a cloudy day to fill in a pixel). They studied data from 754 meteorological stations in Austria, from January 2003 through December 2005, to evaluate these approaches. 1) Using a combination of Terra (MOD10A1) and Aqua (MYD10A1) snow maps resulted in a 9-21\% decrease in cloud coverage as compared to using Aqua snow maps, alone, over Austria. 2) Using a spatial filter where cloudcovered pixel results were replaced with neighboring cloud-free pixel results provided more views of each pixel, and an annual overall decrease in accuracy of only $0.09 \%$ relative to using their Terra/Aqua combined product, a technique similar to that used by Zhou et al. (2005). 3) The temporal filter uses from 1 to 7 preceding days of snow-cover observations to replace cloud-covered pixel results using both Terra and Aqua data. Using their 1-day filter, cloud coverage was reduced over Austria from $51.7 \%$ to $33.5 \%$, with a small overall decrease in accuracy of the product (from 94.7 to $94.4 \%$ ). Use of the 7-day temporal filter caused a reduction of cloud coverage of $>95 \%$, maintaining an overall accuracy of $>92 \%$ when compared with in-situ data (Parajka \& Blöschl, 2008).

Tong et al. (2009a,b) also developed a method using a spatial filter that reduces coverage and improves the accuracy of snow mapping by $2 \%$ in the Quesnel River basin of British Columbia, Canada. Their technique is effective in reducing cloud cover in the 8-day maximum snow-cover product (MOD10A2). They assessed topographic control on SCF and snow-cover duration.

Gafurov and Bárdossy (2009) developed an innovative six-step method of cloud mitigation for MODIS snow-cover products, MOD10A1 and MYD10A1, in the Kokcha River basin located in the northeastern 
part of Afghanistan. Their first step involves the use of both Terra and Aqua snow products. Successive steps offer further cloud removal. Accuracy was assessed using the MOD10A1 products.

All approaches described above are useful for minimizing cloud cover in the standard MODIS snow-cover map products. The tradeoff in acquiring more snow-cover observations is that it increases the uncertainty in a given snow map on any given day if the observation comes from a previous day.

\subsection{Data assimilation modeling}

Recent advances in remote sensing have enabled the monitoring and measurement of the Earth's land surface at an unprecedented scale and frequency. These satellite observations, however, are discontinuous in time and space and therefore must be integrated with land surface model forecasts to generate spatially and temporally consistent estimates of environmental conditions. The LIS framework was developed with the goal of integrating satellite- and groundbased observational data products with advanced land surface modeling techniques to produce optimal fields of land surface states and fluxes (Kumar et al., 2006, 2008). LIS is an expert system encapsulating a suite of modeling, computational and data assimilation tools to study land surface processes and land atmosphere interactions. It provides a comprehensive infrastructure for sequential data assimilation studies.

The accurate prediction from a land surface model depends in part on the model's representation of physical processes and on the quality of the model inputs and forcings (Kumar et al., 2008). The LIS framework has been used in several data assimilation scenarios, specifically in the assimilation of surface soil moisture (Kumar et al., 2009) and skin temperature. Kumar et al. (2008) investigated the impact of assimilating different types of snow observations using the LIS framework.

\section{Methodology}

To develop the MODIS CGF snow map product, the algorithm uses observations to update the daily product that have $\leq 80 \%$ cloud cover, and tracks day of surface observation. Thus the "view" of the surface has $\leq 80 \%$ cloud cover and is expressed as SCF. This typically results in a nearly-cloud-free map of snow-cover extent 5 to10 consecutive days following its initiation. Persistence of cloud cover following the last view of the surface causes confidence in the accuracy of the CGF snow map to erode as the time since the last view increases. To ensure that each user is aware of the age of the observation that is being used on a per-gridcell basis, each new CGF snow map is provided as a "cloud-persistence count" (CPC) map of the snow observation. This allows the user to gauge the confidence associated with this product at each grid cell. The CPC represents the number of consecutive days of cloud obscuration since the last view of the surface. Fig. 1 is an example of the MODIS CGF daily snow-cover map for 5 February 2008.

The CGF map is made from the MOD10C1 product using SCFs from 20 to $100 \%$. The cloud-cover data from MOD10C1 are used to determine if a cell is cloud obscured. If cloud cover is $\geq 80 \%$ according to the MODIS cloud mask, then the cell is classified as "cloud covered." If a grid cell is cloud covered on the image date, the last view is retained as the observation for the current day. A CPC is recorded for every grid cell and updated each day so that the number of days of cloud cover preceding the image date is tracked. When a view of the surface is obtained after one or more days of cloud cover, the CPC is reset to zero for that grid cell.

Observations of SCFs with $<20 \%$ snow cover are discarded to alleviate snow errors of commission that originated in the snow-cover level-2 (swath) algorithm that are typically caused by snow/cloud confusion or deep cloud shadows on land surface. Those types of errors are obvious in regions and seasons where snow cover is extremely unlikely, thus this filtering of SCFs is done to improve quality of the CGF map. Grid cells with discarded SCFs are replaced with $0 \%$ snow cover. Filtered SCF and CGF maps agree well, including along edges of snow cover where the filtering may cause a minor reduction in snow extent, with other snow maps from sources given in the Background section.

The modeling domain covers a region around the Great Lakes and Red River in the continental United States with a spatial extent from $36^{\circ} \mathrm{N}, 93^{\circ} \mathrm{W}$ to $49^{\circ} \mathrm{N}, 72^{\circ} \mathrm{W}$ at $0.05^{\circ}$ spatial resolution (Fig. 3). The spatial resolution of the modeling domain was chosen to be the same as the resolution of the snow-cover products to avoid the introduction of remapping errors as a result of upscaling or downscaling of the data. The Noah land surface model version 2.7.1 (Ek et al., 2003) is used in the simulations; it employs a snow model formulation with a single layer and simulates the physical processes of temporallyvarying snow density. This allows patchy snow cover to evolve as a function of snow depth and vegetation type. The evolution of snow pack density modeled by Noah is governed via a time dependent snow compaction algorithm, which includes the effects of snowfall. A more detailed description of the Noah snow physics is provided in Koren et al. (1999) and Ek et al. (2003). The initial conditions for the model integrations are generated by performing a land surface model spinup from 1 January 2000 to 1 November 2007. The model integrations are performed from 1 November 2007 to 1 June 2008. Meteorological boundary conditions for both the spinup and model integrations are specified using the North American Land Data Assimilation System (NLDAS) forcing data (Cosgrove et al. 2003).

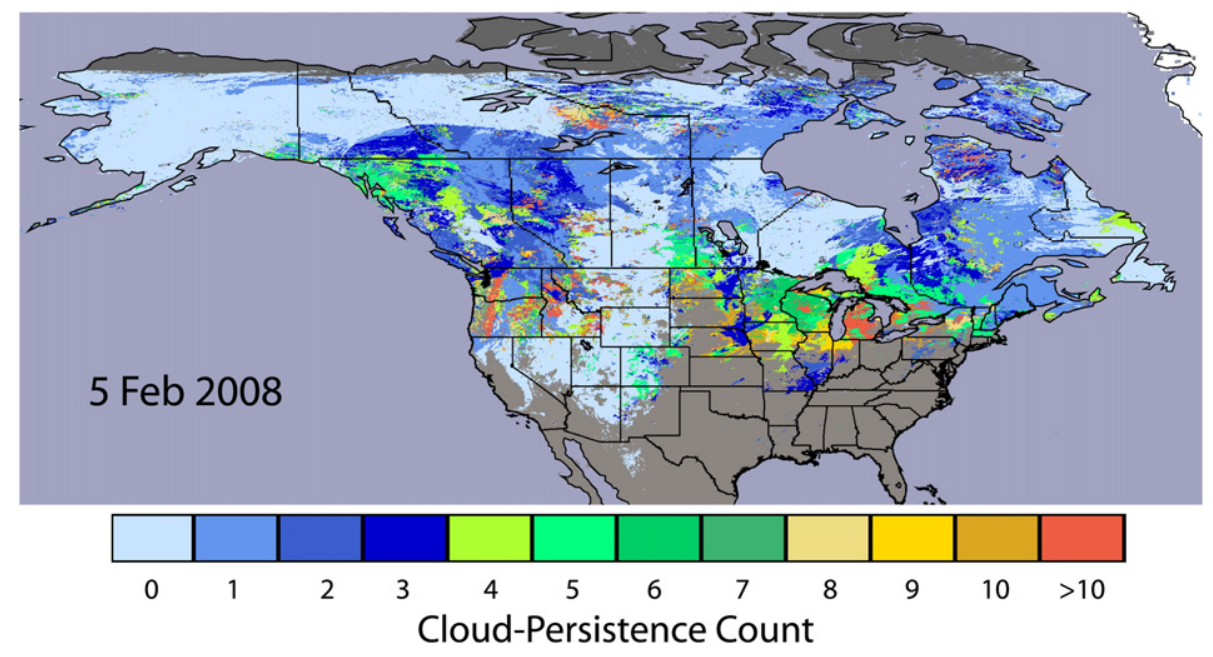

Fig. 1. Cloud-gap-filled (CGF) cloud-persistence count (CPC) snow-cover map, 5 February 2008. Gray areas are not snow covered. 
Assimilation of both MOD10C1 and the CGF snow-cover maps into the land surface model is conducted using the heuristic approach of Rodell and Houser (2004). This directly corrects the SWE fields in the model when there is a mismatch between the satellite observations and the model prediction. If the satellite observation indicates that snow is absent and the model predicts that snow is present, the model-predicted snow is removed. If the satellite observation indicates that snow is present, but snow is absent in the model, a nominal amount of SWE $(10 \mathrm{~mm})$ is added to the model SWE states. The snow depth fields are also updated based on the modeled snow density. The standard MOD10C1 product specifies a cloud mask that indicates the fraction of the land surface that was cloud covered at the time of the satellite overpass. Only observations with $<10 \%$ cloud cover were selected for use in these model runs.

Two different assimilation experiments were conducted using the CGF product, one with a $\mathrm{CPC}=0-5$ days, and the second one with a $\mathrm{CPC}=0$ 3 days. In total, four model integrations were performed: (1) a model simulation with no data assimilation (hereafter referred to as No-DA); (2) a model simulation assimilating the standard MOD10C1 snow-cover product (hereafter referred to as DA-MOD10C1); (3) model simulation assimilating the MODIS CGF snow-cover product with a $\mathrm{CPC}=0-3$ days (hereafter referred to as DA-CGF $(\mathrm{CPC}=3)$ ); and (4) model simulation assimilating the MODIS CGF snow-cover product with a $\mathrm{CPC}=0-5$ days (hereafter referred to as DA-CGF $(\mathrm{CPC}=5)$ ).

\section{Results}

In Fig. 1, each snow-covered grid cell is displayed as a CPC. СРC $=0$ means that the confidence in the automated snow decision for that cell is high since a view of that cell occurred on the image date. $[C P C=0$ does not mean that there is $100 \%$ confidence that snow is present in that grid cell; the snow/no snow value is still subject to the uncertainties of the MOD10C1 snow product as discussed in Hall and Riggs (2007), and by many other authors, some of whom are cited in Hall and Riggs (2007) (see Limitations section).] CPC $=1$ means that a view of that cell was not possible on the day of the image, but was obtained from the previous day, or 4 February 2008. CPC $=2$ means that the surface view was obtained from 2 days earlier, or 3 February 2008 , and so on.

In the CGF product, grid cells with $\mathrm{CPC}=0$ are the same as the corresponding grid cell in the standard MOD10C1 product (for SCF $\geq 20 \%$ ). If the user is willing to accept lower levels of confidence in the snow-cover decision, cells with $\mathrm{CPC}=0-3$ days provide more views each day and a small increase in uncertainty. The user can select the CPC value that is desired. Table 1 shows the average percentage (and number) of snow-covered cells per month, in North America,

Table 1

Average percentage of snow-covered cells per month for which a snow decision was made, in North America (excluding Greenland), when $C P C=0$ and when $C P C=0$ to 3 days for January through May 2008.

\begin{tabular}{llll}
\hline & CPC $=0$ (\# cells) & CPC $=0$ to 3 (\# cells) & \% increase in cells \\
\hline January $^{\mathrm{a}}$ & $23.0(249,283)$ & $46.6(503,718)$ & 102 \\
February & $30.8(333,521)$ & $60.2(651,671)$ & 95 \\
March & $29.6(320,064)$ & $57.7(624,307)$ & 95 \\
April & $29.3(317,319)$ & $53.7(581,505)$ & 83 \\
May & $13.3(143,985)$ & $27.2(294,635)$ & 105 \\
\hline
\end{tabular}

Total number of cells for which a snow decision was made is in parentheses, and the total number of cells for North America, excluding Greenland, is 1,082,206. Column 1 $(\mathrm{CPC}=0)$ provides exactly the same result as does the MOD10C1 map when the MOD10C1 snow-cover fraction (SCF) $\geq 20 \%$. Also shown is the percent increase in cells observable for each month if $\mathrm{CPC}=0$ to 3 days is used compared to $\mathrm{CPC}=0$. Since it takes a few days to spin up the algorithm, if it starts on 1 January, the clouds are pretty much cleared by 11 January and thus the table shows only results from 12 to 31 January (cloud-free snow maps).

a Based on 12-31 January. excluding Greenland in 2008. This demonstrates the large decrease in cloud obscuration in the snow-cover map that is possible if $\mathrm{CPC}=0-3$ days is used, allowing up to four days of observations to be used for a cell instead of just the current day $(\mathrm{CPC}=0)$.

In January through May 2008, cloud obscuration is a major problem in the MOD10C1 maps, with only $\sim 13$ to $31 \%$ of the snowcovered cells mapped (Table 1). An average of $96 \%$ increase in cells mapped as snow covered is shown in Table 1 for the months of January through May 2008 using the CGF maps with CPC $=0$ to 3 days, thus dramatically increasing the number of cells mapped as snow covered in North America.

In Fig. 2A-F, we show comparisons of snow maps of North America from MOD10C1 (Figs. 2A, C and E) and the CGF snow maps (Figs. 2B, D and F) for 5, 6 and 7 February 2008, respectively. With the exception of Alaska and northwestern Canada, most of the area shown is covered by clouds according to the MODIS cloud mask on each of the three days. However, using $\mathrm{CPC}=0-3$ days from the CGF maps (meaning that the snow cover reported was obtained up to 3 days prior to the date shown, or 2 February in the case of the 5 February map), the observable area was increased by $~ 59 \%$ or more on each day (Table 2 ).

\subsection{Data assimilation experiments and results}

This section presents a description of the data assimilation experiments designed to evaluate the potential improvements from using the MODIS CGF snow-cover product as compared to the MOD10C1 standard product. The assimilation integrations utilize the snow-cover data to correct the modeled SWE and snow depth fields. By estimating the improvements in these modeled snow fields as a result of assimilating snow-cover observations, we provide an indirect evaluation of the snow-cover products.

In our modeling domain, there are approximately 1500 groundbased co-op stations as shown in Fig. 3, which provide estimates of daily averaged snow depth measurements (note that not all stations report daily). To assess the performance of the model and assimilation integrations, root mean square errors (RMSE) and bias errors were computed for the four model integrations using the co-op data. Since our metric of interest is the improvement as a result of data assimilation, the results are presented as percentage improvements in RMS and "bias" errors. We define bias to be observation value minus the model forecast. These improvement metrics are computed as the difference in domain-averaged RMSE (or bias) between the model integration (noDA) and the assimilation integration, normalized by the RMSE or bias of the model integration. The improvement metric is positive if the assimilation integration provides better snow depth estimates relative to the no-DA integration, and negative if the assimilation degrades the fields. Note also that the improvement metric, as defined here, is valid only if the error estimates (specifically the bias measures) are nonnegative. In our simulations, the domain-averaged bias estimates were always found to be positive and therefore we employ this definition to report both bias and RMSE improvements.

Figs. 4 and 5 show domain-averaged estimates of percentage RMS and bias error improvements from the data assimilation integrations, presented both at the monthly timescale, and for the entire simulation period. It can be noted that all assimilation integrations provide improvements in RMSE and bias estimates over the no-DA simulation, though the magnitude of improvements from the integrations varies. The figures also indicate the key result that greater improvements were obtained when CGF maps are used, compared to the use of the standard MOD10C1 product. As noted earlier, these improvements in the snow depth fields resulting from the incorporation of snow-cover information provide an indirect assessment of the MODIS snow-cover datasets.

The maximum RMSE improvements are $~ 5 \%$ and the average RMSE improvement is $\sim 1.5 \%$ when the CGF product is used compared to using no data assimilation. Moreover, the simulations show considerable 

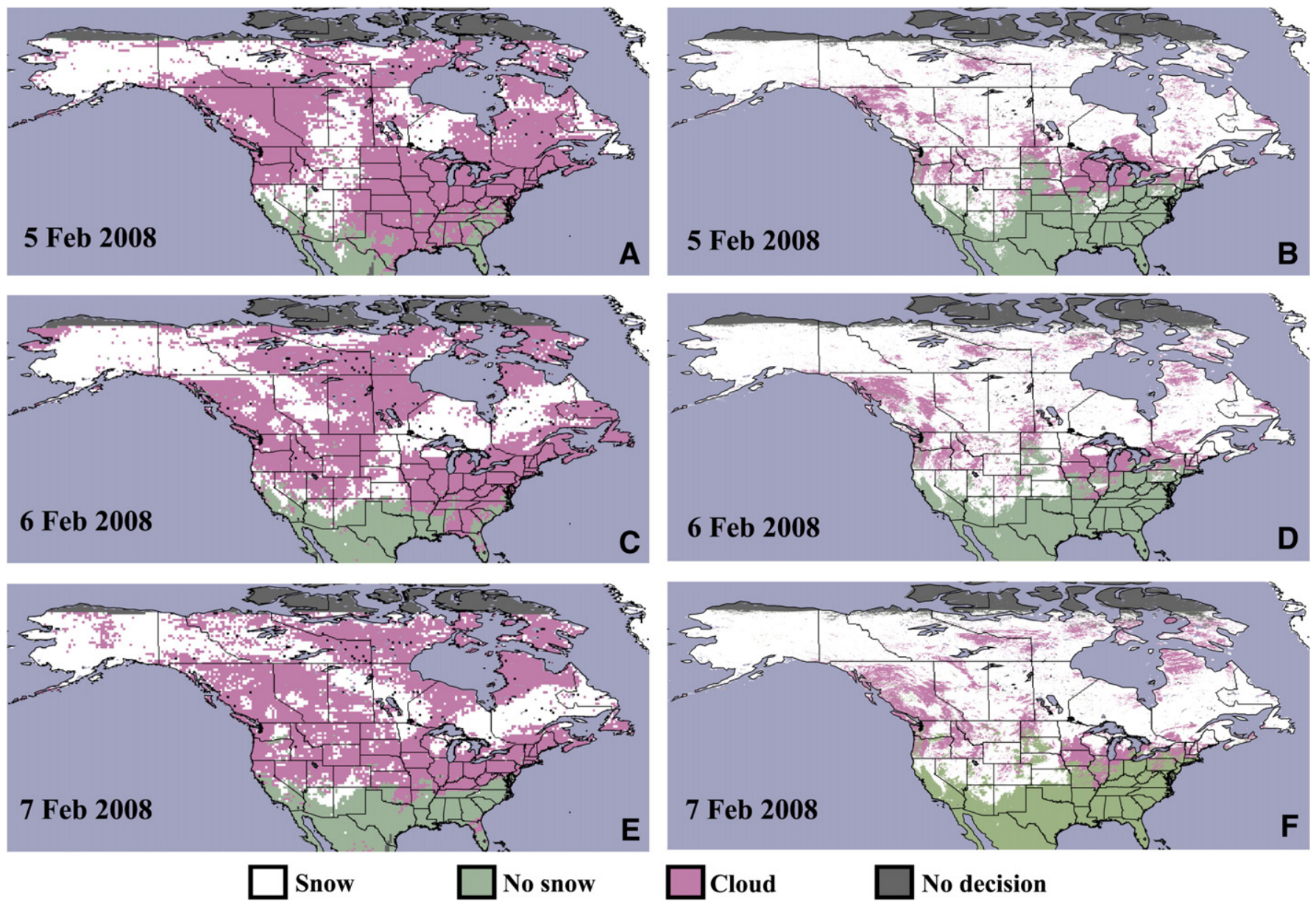

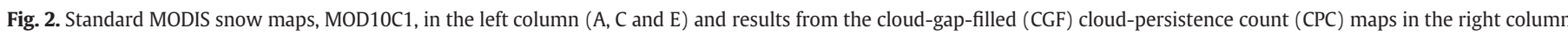
(B, D and $\mathrm{F}$ ), using $\mathrm{CPC}=0-3$ days, for the same days.

improvement in the bias errors, with a maximum of $\sim 36 \%$ and an average improvement of $\sim 11 \%$ when the CGF product is used compared to using no data assimilation. This indicates that the default model simulation (no-DA) has a systematic bias compared to the co-op observations and the assimilation integrations help in correcting these errors. On the other hand, the contribution of data assimilation toward correcting the random errors is small, and this is evident from the minor improvements in the RMSE values.

The domain-averaged percentage bias improvement for the entire time period is $\sim 3 \%$ when the standard MOD10C1 product is used, whereas the CGF product generates percentage bias improvements of 11 and $12 \%$ for $\mathrm{CPC}=0-3$ and $0-5$ days, respectively. At the monthly timescale, CGF-based assimilation integrations provide improvements up to $36 \%$ whereas the maximum such improvement using the MOD10C1 product is $\sim 7 \%$. It is encouraging that the simulation with a $\mathrm{CPC}=0-5$ days $(\mathrm{DA}-\mathrm{CGF}(\mathrm{CPC}=5)$ ) shows improvement over the $\mathrm{CPC}=0-3$ days $(\mathrm{DA}-\mathrm{CGF}(\mathrm{CPC}=3)$ ) simulation.

As mentioned earlier, the assimilation algorithm of Rodell and Houser (2004) is designed to update snow fields if the model and the

Table 2

The percentage of snow observed is compared using the standard MODIS daily snow map, MOD10C1, and the CGF map when CPC $=0$ to 3 days, for the maps of North America shown in Fig. 2.

\begin{tabular}{llll}
\hline Date & \% snow mapped using MOD10C1 & \% snow mapped using CGF & \% increase \\
\hline 5 Feb. & 39.56 & 63.99 & 62 \\
6 Feb. & 40.04 & 66.74 & 67 \\
7 Feb. & 40.73 & 64.76 & 59 \\
\hline
\end{tabular}

observations disagree on the presence or absence of snow. As a result, the algorithm is likely to provide maximum improvements during the snow accumulation and evolution, and snow melt periods. These trends can be observed in both Figs. 4 and 5, which show higher improvements during November (snow accumulation period) and during March (snowmelt period), with relatively smaller improvements during the winter months. Fig. 5, however, also shows an anomalously-large bias improvement during January. This is likely a result of the fact that we considered only one snow season. Further, it was also verified that during this snow season, several transitions between snow covered and non snow-covered conditions occurred during the month of January in our modeling domain.

\section{Limitations}

As with any product that is designed to make assumptions about the conditions beneath cloud cover, the new MODIS CGF daily snowcover product has limitations. An observation of the surface, whether clear or cloud obstructed, persists in the CGF snow map through subsequent day(s) of cloud cover. Persistence of cloud cover decreases confidence in the CGF-reported state of the surface (snow or not snow). Changes in snow-cover extent, spatially and/or temporally, will be hidden by days of cloud cover, and thus will not be captured in the daily CGF. The CPC associated with each grid cell may be used as an indicator of confidence in the CGF. When clear conditions prevail the CPC is low indicating high confidence in observations, and alternatively, when cloudy conditions persist the CPC increases, indicating lower confidence in the CGF-reported state of the surface (snow or not snow). 


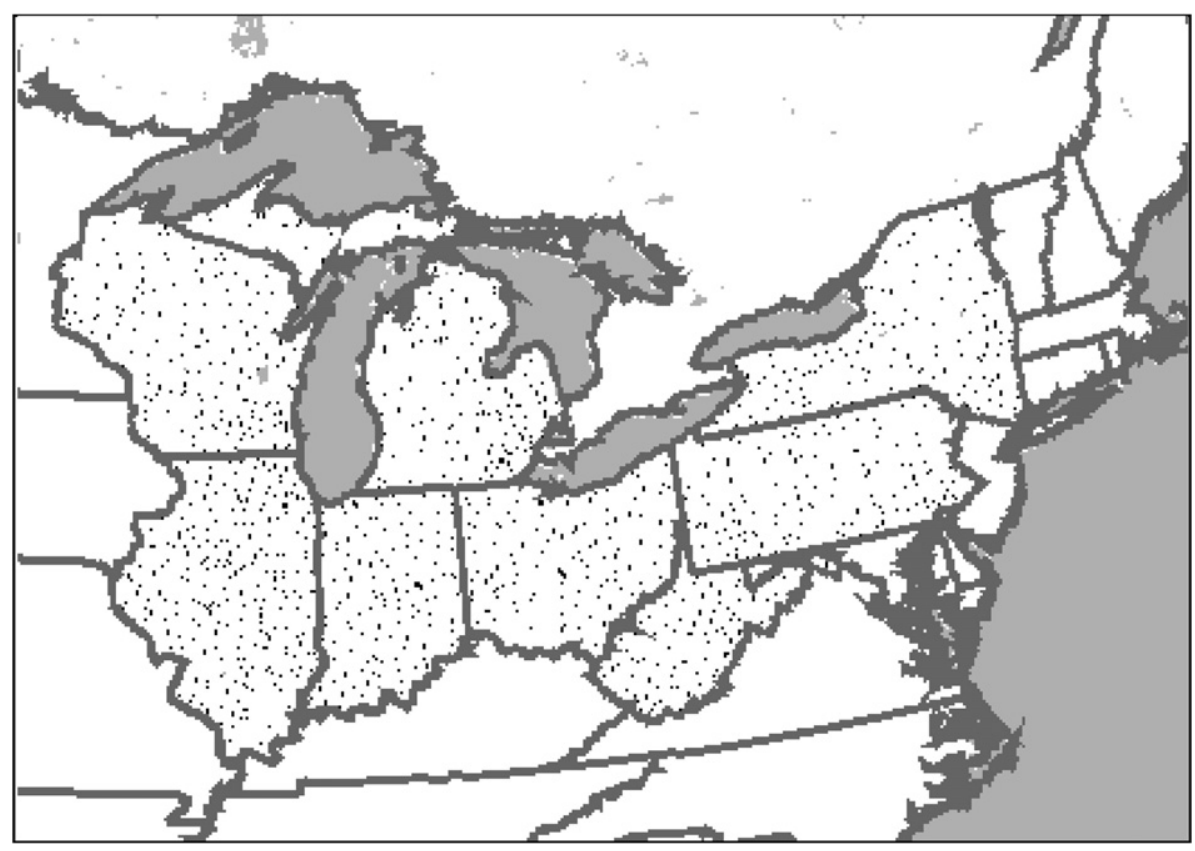

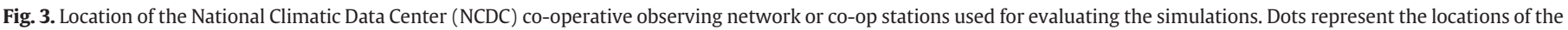
co-op stations.

It warrants repeating that when the CGF maps provide a $\mathrm{CPC}=0$ (see 5 February 2008 (Fig. 2)), that does not mean that we are $100 \%$ confident that the percentage of SCF reported in that cell is accurate. Rather, we are $100 \%$ confident that a view of the surface ( $80 \%$ or less cloud cover) was obtained on that day. The snow/no snow value is still subject to the uncertainties of the MOD10C1 snow product (Hall \& Riggs, 2007).

\section{Discussion}

The "gold standard" of the MODIS standard snow-cover products is the 500-m resolution 5-min swath product, MOD10_L2, that is the first in the snow-cover product suite, with the time of image acquisition provided. The next in the suite of products is the $500-\mathrm{m}$ resolution daily tile (or gridded) product in the sinusoidal projection, called MOD10A1 (Riggs et al., 2006). MOD10A1 is the most-frequently

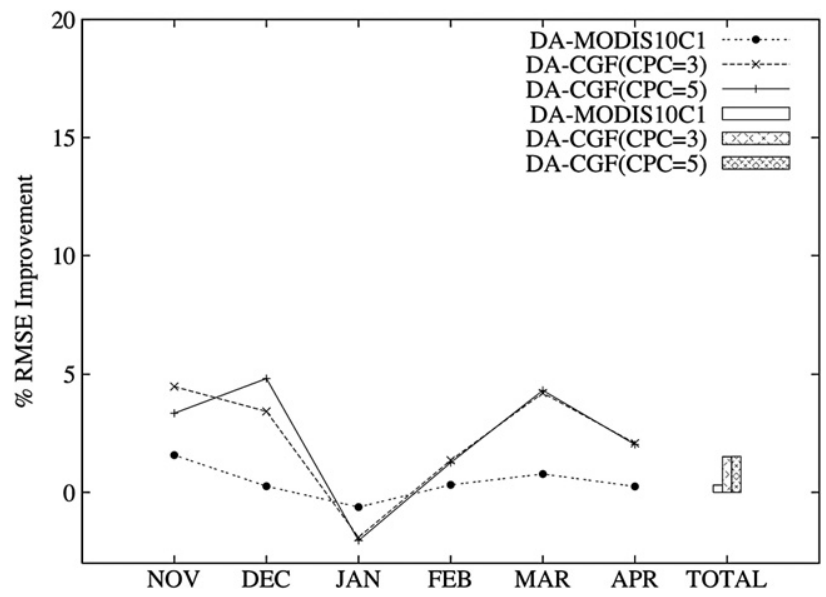

Fig. 4. Percentage RMSE improvements from the data assimilation integrations at the monthly timescale. DA-MOD10C1 refers to the assimilation integration using the standard MOD10C1 product, $\mathrm{DA}-\mathrm{CGF}(\mathrm{CPC}=3)$ and $\mathrm{DA}-\mathrm{CGF}(\mathrm{CPC}=5)$ represent assimilation integrations using the CGF product with a $\mathrm{CPC}=0-3$ and $0-5$ days, respectively. The boxes represent the average error estimates for the entire simulation period. ordered standard MODIS snow-cover product (NSIDC, written communication, 2009). But if a user requires a cloud-reduced or cloud-free product, and will accept the attendant greater uncertainty in a snow decision for a grid cell that may not be determined from the exact date of the snow-cover map, the new CGF product will be very useful. In the near future, a CGF algorithm will be developed for the MOD10A1 daily products to provide CGF products at $500-\mathrm{m}$ resolution. Having the CPC specified for each grid cell "forces" the user to acknowledge mapping limitations imposed by cloud cover in the CGF map product, and is useful for modelers.

This new product is based on a simple accounting of days since the last observation, an approach that has proven to be useful for mapping snow cover and for other applications. Advantages of the CGF product are many; for example: 1 ) it utilizes a proven technique for filling in data gaps that is straightforward and easy to implement and understand; 2) it uses only one data product (Terra MODIS or Aqua

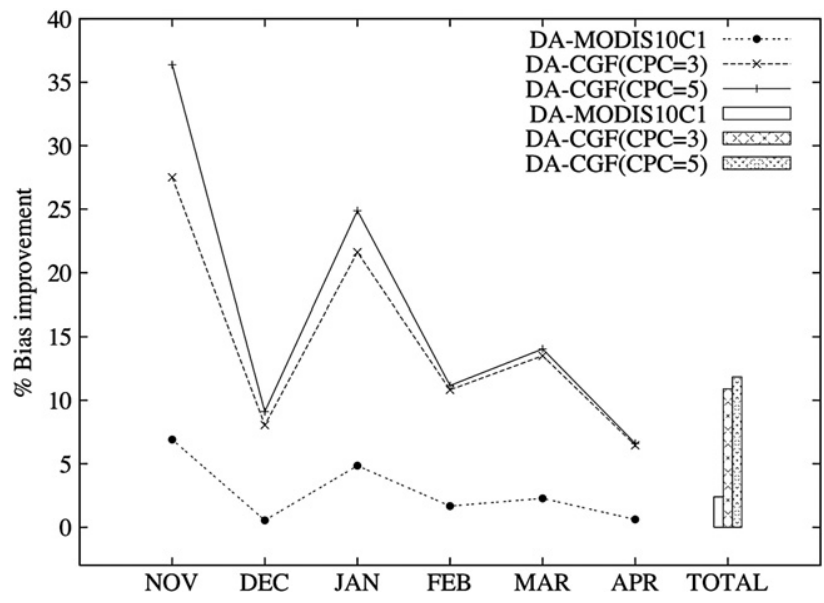

Fig. 5. Percentage bias error improvements from the data assimilation integrations at the monthly timescale. DA-MOD10C1 refers to the assimilation integration using the standard MOD10C1 product, $\mathrm{DA}-\mathrm{CGF}(\mathrm{CPC}=3)$ and $\mathrm{DA}-\mathrm{CGF}(\mathrm{CPC}=5)$ represent assimilation integrations using the CGF product with a $\mathrm{CPC}=0-3$ and $0-5$ days, respectively. The boxes represent the average error estimates for the entire simulation period. 
MODIS) so that in the future, loss of data from one of the satellites will not cause disruption of the other product - the CGF product will still be produced using the other MODIS instrument; and, 3 ) it is highly suited for use in hydrological and global models.

The MODIS snow-cover product, MOD10C1, has been blended with the Advanced Microwave Scanning Radiometer for EOS (AMSR-E) standard snow product (Kelly, 2009) to provide daily maps of snow cover and SWE in a product called the Air Force Weather Agency (AFWA)-NASA snow algorithm (ANSA) (Foster et al., in press). But the resolution of that product is currently $25 \mathrm{~km}$ and passive-microwave data cannot be used reliably for mapping thin, dry snow or very wet snow, due to inherent limitations in the passive-microwave data and algorithms (see for example, Chang et al., 1987; Basist et al., 1996). This can be especially problematic at the snowline during the spring snowmelt period. And the coarse resolution of the passive-microwave data is not ideal for mapping snow at and near the continental snowline (Hall et al., 2007), so there can be large areas of snow cover that are not mapped by the passive-microwave sensors. To increase the number of snow-cover observations, the CGF MODIS daily snow-cover product will replace MOD10C1 as input to the ANSA product. It is anticipated, based on the work shown herein, that this will improve the snow mapping accuracy of the ANSA product.

\section{Conclusions}

Through a time series of snow-cover maps, and data assimilation runs, we show that the use of information on snow cover from clear days prior to the day of image acquisition provides a more complete snow-cover map than the original MOD10C1 snow-cover map. For the months of January through April 2008 when CGF maps are employed using a $\mathrm{CPC}=0-3$ days, there is an average of $96 \%$ increase in the number of snow-covered cells observable as compared to using the standard MODIS product, MOD10C1 (for SCF $\geq 20 \%$ ). The CPC map provides the age of an observation based on cloud-cover persistence on a per-grid-cell basis, thus permitting the user to select the appropriate range of cloud-cover persistence days for his/her specific needs.

The effectiveness of the CGF product is evaluated by conducting a suite of data assimilation experiments using the community Noah LSM in the NASA LIS framework. These data assimilation experiments employ the snow-cover information to improve the model's characterization of snow depth and SWE fields. As a result, the data assimilation experiments help in providing an indirect evaluation of the snow-cover datasets. Use of the CGF product provides an increased number of usable grid cells in the data assimilation system as compared to using the MOD10C1 standard snow-cover product, and shows greater improvements in the RMS and bias errors than when the CGF snow-cover maps are input to the model. The domain-averaged percentage bias improvement for the entire time period is $\sim 3 \%$ for the standard MOD10C1 product, whereas the CGF product generates percentage bias improvements of 11 and $12 \%$ for $C P C=0-3$ and $0-$ 5 days, respectively. The improvements in bias errors suggest that the Noah LSM largely underestimates the evolution of SWE and snow depth fields, and that the assimilation integrations contribute to correcting this systematic error. This gap-filling strategy is a useful and for generating cloud-reduced or cloud-free MODIS daily snow-cover maps.

\section{Acknowledgments}

The authors thank Jeff Miller of Wyle Information Services L.L.C. for programming support, and Janet Chien for image processing support. We also thank Dr. Chris Derksen of Environment Canada, and three anonymous reviewers for insightful comments that allowed us to improve the paper.

\section{References}

Ackerman, S. A., Strabala, K. I., Menzel, P. W. P., Frey, R. A., Moeller, C. C., \& Gumley, L. E. (1998). Discriminating clear sky from clouds with MODIS. Journal of Geophysical Research, 103(D24), 32141-32157.

Armstrong, R. L., \& Brodzik, M. J. (2001). Recent Northern Hemisphere snow extent: A comparison of data derived from visible and microwave satellite sensors. Geophysical Research Letters, 28(19), 3673-3676.

Basist, A., Garrett, D., Ferraro, N., Grody, N., \& Mitchell, K. (1996). A comparison between snow cover products derived from visible and microwave satellite observations. Journal of Applied Meteorology, 35(2), 163-177.

Bavera, D., \& Michele, C. D. (2009). Snow water equivalent estimation in the Mallero basin using snow gauge data and MODIS images and fieldwork validation. Hydrological Processes, 23, 1961-1972. doi:10.1002/hyp. 7328.

Borak, J. S., \& Jasinski, M. F. (2009). Effective interpolation of incomplete satellitederived leaf-area index time series for the continental United States. Agricultural and Forest Meteorology, 149, 320-332.

Brown, R. D. (2000). Northern Hemisphere snow cover variability and change, 1915-97. Journal of Climate, 13(13), 2339-2355.

Brown, L., Thorne, R., \& Woo, M. -K. (2008). Using satellite imagery to validate snow distribution simulated by a hydrological model in large northern basins. Hydrological Processes, 22(15), 2777-2787. doi:10.1002/hyp. 6999.

Chang, A. T. C., Foster, J. L., \& Hall, D. K. (1987). Nimbus-7 SMMR derived global snow cover parameters. Annals of Glaciology, 9, 39-44.

Cosgrove, B. A., Lohmann, D., Mitchell, K. E., Houser, P. R., Wood, E. F., Schaake, J. C., et al. (2003). Real-time and retrospective forcing in the North American Land Data Assimilation System (NLDAS) project. Journal of Geophysical Research, 108(D22), 8842. doi:10.0129/2002JD003118.

Déry, S. J., Salomonson, V. V., Stieglitz, M., Hall, D. K., \& Appel, I. (2005). An approach to using snow areal depletion curves inferred from MODIS and its application to land-surface modelling in Alaska. Hydrological Processes, 19, 2755-2774. doi:10.1002/hyp5784.

Ek, M., Mitchell, K. E., Yin, L., Rogers, E., Grunmann, P., Koren, V., et al. (2003). Implementation of Noah land surface model advances in the NCEP operational mesoscale Eta model. Journal of Geophysical Research, 108, 8851. doi:10.1029/2002JD003296.

Foster, J. L., Hall, D. K., Eylander, J. B., Riggs, G. A., Nghiem, S. V., Tedesco, M., Kim, E. J., Montesano, P. M., Kelly, R. E. J., Casey, K. A., \& B. J. Choudhury. (in press). A blended global snow product using visible, passive microwave and scatterometer satellite data, International Journal of Remote Sensing.

Frei, A., \& Robinson, D. A. (1999). Northern Hemisphere snow extent: Regiona variability 1972-1994. International Journal of Climatology, 19(14), 1535-1560.

Gao, F., Morisette, J. T., Wolfe, R. E., Ederer, G., Pedelty, J., Masuoka, E., et al. (2008). An algorithm to produce temporally and spatially continuous MODIS-LAI time series. IEEE Geoscience and Remote Sensing Letters, 5(1), 60-64.

Gafurov, A., \& Bárdossy, A. (2009). Cloud removal methodology from MODIS snow cover product. Hydrology and Earth System Sciences, 13(7), 1361-1373.

Hall, D. K., Riggs, G. A., Salomonson, V. V., DiGirolamo, N. E., \& Bayr, K. J. (2002). MODIS snow-cover products. Remote Sensing of Environment, 83, 181-194.

Hall, D. K., \& Riggs, G. A. (2007). Accuracy assessment of the MODIS snow-cover products. Hydrological Processes, 21, 1534-1547.

Hall, D. K., Montesano, P. M., Foster, J. L., Riggs, G. A., Kelly, R. E. J., \& Czajkowski, K. (2007). Preliminary validation of the AFWA-NASA blended snow-cover product. Proceedings of the 64th Eastern Snow Conference, 28 May-1 June 2007, St. John's, Newfoundland, Canada.

Helfrich, S. R., McNamara, D., Ramsay, B. H., Baldwin, T., \& Kasheta, T. (2007) Enhancements to, and forthcoming developments in the Interactive Multisensor Snow and Ice Mapping System (IMS). Hydrological Processes, 21, 1576-1586. doi:10/1002/hyp. 6720 .

Kelly, R. E. J. (2009). The AMSR-E snow depth algorithm: Description and initial results. Japanese Journal of Remote Sensing, 29(1), 307-317. (GLI/AMSR Special Issue).

Koren, V., Shaake, J. C., Mitchell, K. E., Duan, Q. Y., Chen, F., \& Baker, J. (1999). A parameterization of snowpack and frozen ground intended for NCEP weather and climate models. Journal of Geophysical Research, 104, 19,569-19,585.

Kumar, S. V., Peters-Lidard, C., Tian, V., Houser, P., Geiger, J., Olden, S., et al. (2006). Land information system: an interoperable framework for high resolution land surface modeling. Environmental Modeling Software, 21, 1402-1415.

Kumar, S. V., Reichle, R. H., Peters-Lidard, C. D. Koster, R. D., Zhan, X, Crow, W. T. et al. (2008). A land surface data assimilation framework using the land information system: Description and applications. Advances in Water Resources, 31, 1419-1432. doi:10.1016/j.advwatres.2008.01.013.

Kumar, S. V., Reichle, R. H., Koster, R. D., Crow, W. T., \& Peters-Lidard, C. D. (2009). Role of subsurface physics in the assimilation of surface soil moisture observations. Journal of Hydrometeorology. doi:10.1175/2009JHM1134.1.

McGuire, M., Wood, A. W., Hamlet, A. H., \& Lettenmaier, D. P. (2006). Use of satellite data for streamflow and reservoir storage forecasts in the Snake River Basin. Journal of Water Resources Planning and Management, 132(2), 97-110.

Parajka, J., \& Blöschl, G. (2008). Spatio-temporal combination of MODIS images - Potential for snow cover mapping. Water Resources Research, 44. doi:10/1029/2007WR006204

Platnick, S., King, M. D., Ackerman, S. A., Menzel, W. P., Baum, B. A., Riédi, J. C., \& Frey, R. A. (2003). The MODIS cloud products: Algorithms and examples from Terra. IEEE Transactions on Geoscience and Remote Sensing, 41(2), 459-473.

Ramsay, B. (1998). The interactive multisensor snow and ice mapping system. Hydrological Processes, 12(10-11), 1537-1546.

Riggs, G. A., Hall, D. K., \& Salomonson, V. V. (2006). MODIS snow products user guide http://modis-snow-ice.gsfc.nasa.gov/sug_c5.pdf

Riggs, G. A., \& Hall, D. K. (2003). Reduction of cloud obscuration in the MODIS snow data product. Proceedings of the 60th Eastern Snow Conference, Sherbrooke, Québec, 4-6 June, 2003 (pp. 205-212). 
Robinson, D. A., Bamzai, A., \& Ramsay, B. (2001). Evaluating Northern Hemisphere snow cover during the satellite era: Variations in extent and associations with temperature. Proceedings 12th symposium on global change and climate variations, Albuquerque, NM, 14-18 January 2001 (pp. 36-39).

Rodell, M., \& Houser, P. R. (2004). Updating a land surface model with MODIS derived snow cover. Journal of Hydrometeorology, 5(6), 1064-1075.

Romanov, P., \& Gutman, G. (2000). Automated monitoring of snow cover over North America with multispectral satellite data. Journal of Applied Meteorology, 39, 1866-1880.

Tekeli, A. E., Akyurek, Z., Sorman, A. A., Sensoy, A., \& Sorman, A. U. (2005). Using MODIS snow-cover maps in modeling snowmelt runoff processes in the eastern part of Turkey. Remote Sensing of Environment, 97, 216-230.

Tekeli, Y., \& Tekeli, A. E. (submitted for publication). A technique for improving snow cover monitoring in Eastern Turkey using MODIS standard snow products, Iranian Journal of Science and Technology Transaction B: Engineering.

Tong, J., Déry, S. J., \& Jackson, P. L. (2009). Topographic control of snow distribution in an alpine watershed of western Canada inferred from spatially-filtered MODIS snow products. Hydrology and Earth System Sciences, 13, 319-326.

Tong, J., Déry, S. J., \& Jackson, P. L. (2009). Interrelationships between MODIS/Terr remotely sensed snow cover and the hydrometeorology of the Quesnel River Basin, British Columbia, Canada. Hydrology and Earth System Sciences, 13, 1439-1452.
Wang, L., Sharp, M., Brown, R., Derksen, C., \& Rivard, B. (2005). Evaluation of spring snow covered area depletion in the Canadian Arctic from NOAA snow charts. Remote Sensing of Environment, 95(4), 453-463.

Wang, X., Xie, H., Liang, T., \& Huang, X. (2009). Comparison and validation of MODIS standard and new combination of Terra and Aqua snow cover products in northern Xinjiang, China. Hydrological Processes, 23(3), 419-429. doi:10.1002/hyp. 7151.

Wang, X., \& Xie, H. (2009). New methods for studying the spatiotemporal variation of snow cover based on combination products of MODIS Terra and Aqua. Journal of Hydrology, 371, 192-200. doi:10.1016/j.jhydrol.2009.03.028.

Wildt, M. R., Seiz, G., \& Gruen, A. (2007). Operational snow mapping using multi temporal Meteosat SEVIRI imagery. Remote Sensing of Environment, 109, 29-41.

Zhao, H., \& Fernandes, R. (2009). Daily snow cover estimation from Advanced Very High Resolution Radiometer Polar Pathfinder data over Northern Hemisphere land surfaces during 1982-2004. Journal of Geophysical Research, 114(D05113). doi:10.1029/2008JD011272.

Zhou, X., Xie, H., \& Hendrickx, J. M. H. (2005). Statistical evaluation of remotely sensed snow-cover products with constraints from streamflow and SNOTEL measurements. Remote Sensing of Environment, 94, 214-231. 